non-elective, to regulate the mode of admission of patients, and to prescribe what furniture, fixtures, and conveniences shall be provided. These powers are of so extensive a character, that they should be clearly defined by statute, and not left to the discretion of a board which may possibly use them in a crotchety and despotic manner. The Legislature has already seen fit to withdraw, in a great measure, the treatment of the insane poor from the Poor-law authorities, and to vest it in bodies specially constituted for the purpose. But these bodies-called asylum visitors in England, and district boards in Scotland-are elected in the former country from the Justices, and in the latter from the Commissioners of Supply, in accordance with distinct statutory provisions. With them rests the right, subject simply to the approval of the Commissioners in Lunacy, of arranging the districts, erecting the asylums, and providing for the proper care and treatment of the insane poor. In the event of neglect by the visitors or district boards to erect an usylum, the Commissioners are authorised to apply to the Secretary of State, or the Court of Session, for authority to compel them. But neither in England nor in Scotland have the Conumissioners power to require that medical appliances or particular articles of furniture shall be supplied. Their functions are limited to visitation and reporting; but it is free to the visitors in England, and to the district boards in Scotland, to adopt or reject any of the recommendations which the reports of the Commissioners may contain. The results of this system, however, have been so favorable, that in no country in the world are the asylums for the insane so well conducted as in Great Britain. IVe hold, then, that the boards for the management of the proposed metropolitan asylums should be nominated under direct statutory authority, and nowise at second-hand by the Poor-law Board. The evils of the present system have, we believe, arisen from throwing the powers of the guardians chiefly into the hands of men of narrow education and restricted views, who are incapable of acting in an enlightened and liberal spirit. To avoid this error, the new boards should be elected by a higher class of ratepayers-by such, perhaps, as are assessed on an annual value of at lesst $\mathcal{E} 100$; but it would be a mistake to require a similar, or indeed any fixed, amount of annual assessment as a qualification for the district board. A provision of this kind might lead to the exclusion of the men best calculated for the satisfactory discharge of the duties-of professional men, for instance, who were still on the threshold of their career, with knowledge and leisure, but without funds to live in a high-rented house.-Scotsman, March 7th.

\title{
The Supervision of Lunatics in Private Dwellings.
}

Year by year, the difficulties of making proper provision for the care of the increasing numbers of the insane poor grow more and more formidable. The last Report of the English Commissioners in Lunacy, telling as it does of the frequent enlargements of existing asylums, of the building of new asylums, and of the continuing pressure for increased accommodation, repeats an oft-told tale, which has ceased to excite attention only because of its familiarity. Of forty-five county and borough asylums in England, more than half are nearly full, quite full, or more than full; while those that have yet some accommodution left are not likely to bave it long, at the present steady rate of yearly increase in the number of the pauper insane. No wonder that a feeling has grown up in some minds, and is now finding active expresssion in different quarters, that some means should be adopted of relieving the pressure on the overgrown and overcrowded asylums, other than the multiplication of their numbers and the increase of their size. With this aim, the system of placing insane patients in private dwellings, 
under suitable regulations, has been advocated; and we have more than once directed attention to the proposal, not only because of the promise which it offers of getting rid of a fast-growing difficulty, but because it assuredly requires careful consideration ere it be sanctioned and carried into effect. The last Report of the Scotch Lunacy Board furnishes some valuable data for the formation of a judgment upon a question which has hitherto been discussed on theoretical grounds, rather than from a practical point of view.

In Scotland there are at the present time upwards of 1600 pauper insane persons living in private dwellings at a moderate cost, against 2299 pauper insane maintained in public asylums at a more than double cost. What, then, is the condition of these single patients? We learn from the full reports of the Deputy Commissioners, whose work it is to visit them, to in. spect the accommodation given them, and regularly to supervise their treatnent, that their condition, bad as it unquestionably was some years ago, has now been rendered eminently satisfactory. Indeed, Dr. Mitchell, one of the Deputy Commissioners, can now venture to say confidently that for 1500 of these incurable and harmless insane living in private dwellings a reason. able provision has been made, and that their happiness and comfort would not be increased by any other mode of management. "They enjoy life more," he adds, "and will live longer than they would do if placed either in poorhouses or asylums; and to leave them where they are is the course which is at once humane and economical." In face of this official declaration, it will be necessary to pause before rejecting on theoretical grounds in England a plan which seems to have been justified by such complete practical success in Scotland.

If any steps be taken in the same direction in this country-if the experiment be tried of placing some of the harmless insane in private dwellings, and thus opening an outlet of relief to the overcrowded asylums-it will be of prime and essential importance to provide most stringently for the frequent and systematic supervision of them. There should certainly be appointed officers like the Deputy Commissioners of Scotland, or like the Chancery Visitors of England, whose duty it should be to visit regularly these single patients, and to examine into their treatment; and not only so, but to search out the many insane persons who are undoubtedly now living illegally in different parts of the country, unknown to the Commissioners, without proper orders and medical certificates. The law enacts that every Chancery patient must be seen by the proper authorities once each quarter, and that every patient in a private asylum must be visited officially at least six times a year-by the Commissioners in Lunacy, if the asylum be within the metropolitan district ; by the Visiting Justices and the Commissioners, if it be a provincial asylum. What is necessary for patients under the jurisdiction of the Court of Chancery, or in private asylums, is still more necessary for single patients living under the charge of any irresponsible person who may choose to receive them for profit, and under circumstances in which the danger of abuses growing up is very great. Indeed, the experience of the Scotch Lunacy Board has shown conclusively that the cliaracter of the treatment of insane persons in private houses is entirely dependent on the completeness and adequacy of official inspection. The horrible and wretched state of the Scotch single patients, before a system of regular inspection was instituted, as compared with their present comfortable and contented condition-many of them now being regularly, and some of them even profitably, employedwas very similar to the heartrending condition of the insane in asylums years past, as compared with what it is now, when more enlightened views prevail and better management is ensured. In one of the Scotch counties, in which many single insane patients are now living, satisfactorily eared for 
in every regard, a young woman had lived for many years naked in a frightful cage, while her sister had been allowed to wander almost naked in the woods; another young woman had passed her life constancly chained to a big stone; a man was confined in a bare, windowless cell, which had been built expressly for him; others were found miserably neglected, naked, filthy, and half-starved. It is probable that those who were responsible for this cruel neglect did not err from any actual cruelty of disposition, but from the vulgar, unreasoning horror of the insane, and from an entire ignorance of what their condition demanded. But one great advantage of official inspection was, that it was official instruction; and so it has come to pass in Scotland that, in proportion as those having the care of single patients have been penetrated with better views of their acquirements, the means of their treatment has undergone a remarkable improvement, and now leaves little or nothing to be desired. It is a question, then, which may justly claim to be carefully weighed, whether the extension to England of a system which now works so well in Scotland can be advantageously made; or whether, on the other hand, there are special circumstances in the latter country which render its success there exceptional.

Whether it be thought desirable or not to supplement the present inadequate asylum system in England by placing harmless and incurable lunatics in private dwellings, there can be no manner of doubt of the necessity of a more regular and stringent inspection of single patients than is at present practised, or is indeed practicable with the existing staff of Commissioners. On the lst of January, 1865, there were 212 single patients who had been certified according to tlie statute, and the number had increased to 227 on the 1st of January, 1866. Of these, 43 were Chancery patients, so that there remained only 184 patients whom it was necessary for the Com. missioners to visit. To these, only $19 \mathrm{l}$ visits were made during the year; whence it follows that, with few exceptions, each certified patient was officially seen once in the year. Every one must admit this to be an entirely inadequate inspection. But this is not all: it is quite certain that numbers of insane persons are living as lodgers throughout the country without being legally certified; and though the Commissioners, when they accidentally discover such a case, endeavour to vindicate the law by prosecuting the offenders, yet they are unable, being already so fully occupied, to take proper steps for searching out these illegally placed insane patients, and for affording them the protection which they should rightly have. It needs not the occasional revelations of ill-treatment which occur and excite a painful sensation, to prove that many of the insane are still deprived of that protection to which, by their helpless state, they are peculiarly entitled.-British Medical Journal, January 12.

\section{Medical Psychological Association.}

The Anndal Meeting of the Medico-Psychological Association por 1867 will be held in London, undek the Presidency of Dr. Lockhart ROBERTSON, EARLY IN JULY.

Commonications, \&c. \&c., in reperence to the Annoal Meeting to be addressed to the Honorary Sechetary (Dr. Harrington 'I'Uke), 37, ALbEYARLE Street, LoNDON, W.

\section{Publications Received, 1867.}

'Trousseau's Lectures on Clinical Medicine.' Delivered at the Hôtel-Dieu, Paris, by A. Trousseau, Professor of Clinical Medicine in the Fuculty of Medicine, Paris; Physician to the Hôtel-Dieu; Member of the Inperial Academy XIII. 